\title{
In-depth studies on the modifying effects of natural ageing on the chemical structure of European spruce (Picea abies) and silver fir (Abies alba) woods
}

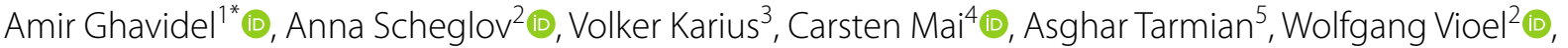 \\ Viorica Vasilache ${ }^{6}$ (ib) and Ion Sandu ${ }^{6,7}$ (I)
}

\begin{abstract}
Wood is usually stable under relatively dry conditions but may still undergo slow deterioration. The type of deterioration and how these processes affect the wood are important questions that need consideration if old wooden structures are to be studied and properly preserved. The aim of this paper is to establish the main structural and morphological differences between new and naturally aged European spruce ( 150-200 years) and silver fir wood ( 150 years). Naturally aged European spruce (a) was sourced from an outdoor part of a building constructed in the seventeenth century and naturally aged European spruce (b) were obtained from a furniture item located in a historical building from the eighteenth century. The principal age-induced changes in fir are the degradation of $\mathrm{C}-\mathrm{O}$ and $\mathrm{C}=\mathrm{O}$ groups in hemicellulose, according to the FTIR analysis. Degradation of cellulose and hemicelluloses was observed for spruce, with a greater effect seen in the indoor aged sample. X-ray photoelectron spectroscopy (XPS) showed that after aging $\mathrm{C}-\mathrm{C} / \mathrm{C}-\mathrm{H}$ peaks were smaller in the spruce and fir samples, while $\mathrm{C}-\mathrm{O}$ and $\mathrm{O}-\mathrm{C}-\mathrm{O}$ peaks were larger. The crystallinity index (Crl) obtained by X-ray diffraction showed that due to weathering the $\mathrm{Crl}$ of naturally aged spruce (a) increased compared to the new wood. The $\mathrm{Crl}$ of the aged spruce (b) and aged fir was lower than in the new woods. The ratios for the spruce sample, which aged indoors, were higher than those for the one aged outdoors. According to the observations made in this study, hemicellulose and cellulose are easily degraded under environmental conditions.
\end{abstract}

Keywords: FTIR spectroscopy, X-ray photoelectron spectroscopy, X-ray diffraction, Natural ageing, Wood

\section{Introduction}

In contrast to most other building and structural materials, wood is a renewable resource available in vast quantities. It has many favourable properties and features such as high strength to weight ratio, unique aesthetic and tactile values and low production cost. Furthermore, it is easy to shape. However, the high inherent heterogeneity

\footnotetext{
*Correspondence: amir.ghavidel.66@gmail.com

${ }^{1}$ Doctoral School of Geosciences, Alexandru loan Cuza University of lasi, lasi, Romania

Full list of author information is available at the end of the article
}

and variability imposes certain challenges in predicting the behaviour of wood in its use as an engineering material. Variations in the anatomy, morphology, and chemical constitution of wood depend on the habitat of trees and affect the properties in service [1-3].

Knowledge of wood aging and property changes in old wood compared to recent wood are crucial for the conservation of wood-based cultural heritage objects and historic wood-built buildings as well as the reuse of old wooden buildings [4]. As an organic material, wood is part of the carbon cycle in nature and its formation and degradation are essential elements of this cycle. 
Wood degradation processes are numerous. It can be degraded under extreme conditions such as heat, frost or high mechanical load. Furthermore, it can be modified by weathering due to UV radiation-induced surface degradation or chemical degradation caused by rain, air pollution or other environmental factors. It can also be biologically degraded by fungi or insects. These degradation processes depend on the conditions, where the wood is stored and used. If the wood is stored in appropriate conditions, degradation can be avoided. However, a longterm ageing phenomenon takes place in wood even if it is kept in most favourable conditions [5-7].

The surface chemistry and wetting properties of uncoated wood surfaces are directly dependent on the wood surface morphology resulting from the wood machining process used as surface processing method. It also varies greatly with, e.g., the cross section and radial or tangential sections [8]. Furthermore, the ageing time of the wood surface is of vital importance for predicting the performance of various woods. Such ageing of the material is mainly related to surface inactivation caused by the migration of extractives from the bulk to the surface and changes in the chemistry due to oxidation of the extractives at the surface [9-14].

For a better understanding of the wood ageing process, some investigations were performed to study the chemical changes of wood during degradation and environmental factors affecting degradation [13-17]. Beyer et al. [18] studied the chemical composition of samples of spruce, fir and oak from a variety of naturally aged construction wood. Differences in non-aged wood samples were observed with respect to lignin and polysaccharide material, as well as cellulose crystallinity, in particular in oak wood samples. The composition of wood extractives from aged and non-ageing wood samples revealed processes of degradation due to oxidation and slight hydrolysis. Furthermore, it was observed that the values of cellulose crystallinity are affected by the content of extractives. According to the findings of Huang et al. [19], ageing mostly induces depolymerization in relation to the control sample, although some results indicate that repolymerization of lignin may occur at extended ageing times. X-ray photoelectron spectroscopy (XPS) is one of several tools that are used to characterize wood surfaces. Among the advantages of XPS are its surface sensitivity with an information depth of approximately $5 \mathrm{~nm}$, identification of nearly all elements and discrimination of bonding states. XPS, also known as electron spectroscopy for chemical analysis (ESCA), involves irradiation of specimens with monochromatic X-rays that cause a removal of a core electron. Popescu et al. [7] investigated the characterization of naturally aged lime wood by XPS and Fourier-transform infrared spectroscopy. They found that significant changes occurred during the first ageing period, with the nearly 150 -year lime wood sample having the highest percentage of carbon atoms and the lowest percentage of oxygen atoms and the $\mathrm{O} / \mathrm{C}$ ratio, respectively.

Attenuated total reflectance Fourier-transform infrared spectroscopy (ATR FTIR) is frequently used to study changes in the surface chemistry of ageing woods to monitor carbonyl group formation, vinyl group formation and changes in crystallinity. The sampling depth of IR radiation, with several micrometres depending on the wavelength and studied material, is orders of magnitude higher than that of XPS. In this study XPS and ATR FTIR spectroscopy were used as complementary techniques to monitor changes in the surface chemistry of naturally aged woods [20, 21].

X-ray diffraction (XRD) is a well-established method for determining the crystallinity of partially crystalline materials. The crystallinity of wood is defined as the weight fraction of crystalline material. Hemicelluloses and lignin are amorphous, but cellulose has both amorphous and crystalline components. The small size of the cellulose crystallites and a large portion of amorphous material in wood make the distinction of the crystalline cellulose signal from the background caused by the amorphous phase difficult. It has been observed that crystallinity and the size of the crystallites are among the parameters that change during the ageing of wood [22]. Additional structural studies are needed to understand how to prevent aging of wood products.

The aim of this paper is to establish the main structural changes between new and naturally aged European spruce and silver fir woods as well as to compare the effects of the ageing conditions (indoor and outdoor) on the chemical structure of spruce and fir wood samples. FTIR spectroscopy and X-ray diffraction were used to investigate the relationship between the cellulose structure and its properties. Furthermore, the effects of ageing on the wood surfaces were investigated with XPS to provide new insights into the chemistry of surface ageing.

\section{Materials and methods \\ Raw materials}

New European spruce (Picea abies) samples were obtained from Sopron, Hungary, new silver fir (Abies alba) samples from Rasht, Iran. The samples were cut from heartwood. Naturally aged European spruce (a) was sourced from an outdoor part of a building constructed in the seventeenth century in the Baila Naval Shipyard on the Danube, Romania. Samples of naturally aged European spruce (b) were obtained from a furniture item located in a historical building from the eighteenth century in Iasi, Romania. The sample was taken from a part 
of the furniture that was not exposed to light. Samples of naturally aged silver fir were taken from a historical furniture item from the eighteenth century in the same building in Iasi, Romania. This sample was located on an outside part of the furniture and was thus exposed to ambient light. For both samples there is no data for the ambient moisture conditions, where the furniture was stored. The samples were carefully selected to avoid defects such as knots, cracks or reaction wood and with an annual growth rings slope less than $5^{\circ}$.

\section{ATR-FTIR analysis}

Square samples with an edge length of $5 \mathrm{~mm}$ and $1 \mathrm{~mm}$ thickness were cut out of each wood. The ATR FTIR spectra were recorded on the Bruker Invenio $R$ spectrometer equipped with a diamond ATR unit (Bruker Optik GmbH, Ettlingen, Germany) in the range of 4000$400 \mathrm{~cm}^{-1}$ using 64 scans at a resolution of $4 \mathrm{~cm}^{-1}$. The samples were pressed on the ATR-crystal with a built-in applicator to ensure a reproducible and constant force. Prior to measurements a background spectrum with an empty specimen compartment was recorded and automatically subtracted from the spectra in the following measurements. For each wood, two samples were analysed, and their spectra averaged. The spectra were baseline corrected and vector-normalised using the software OPUS version 8.2 (Bruker Optik GmbH, Ettlingen, Germany).

\section{XPS analysis}

XPS measurements were performed on the PHI VersaProbe II spectrometer (Ulvac-phi, Inc., Osaka, Japan) using a monochromatic $\mathrm{Al}-\mathrm{K}_{\alpha}$ source at a photon energy of $1486.6 \mathrm{eV}$ and a base pressure of $2 \mu \mathrm{Pa}$. The system measures the $\mathrm{Ag} 3 \mathrm{~d}_{5 / 2}$ peak with a full-width at half-maximum (FWHM) of $0.6 \mathrm{eV}$ at a pass energy of $23.5 \mathrm{eV}$. Active charge compensation was applied during all measurements with a cool cathode electron flood source and low energy argon ions. The measurements were conducted at room temperature without prior surface purification of the sample.

The X-ray power was set to $25 \mathrm{~W}$ with a beam diameter of $100 \mu \mathrm{m}$. The electron take-off angle was kept constant at $45^{\circ}$. A constant analyser energy mode was applied with a pass energy of $23.5 \mathrm{eV}$ and a resolution of $0.1 \mathrm{eV}$ per step for detailed spectra in the $\mathrm{C} 1 \mathrm{~s}$ and O1s region. Survey spectra were recorded at a pass energy of $187.85 \mathrm{eV}$ with $0.4 \mathrm{eV}$ per step.

Data processing and analysis were conducted with the software MultiPak, version 9.9 (Ulvac-phi, Inc.). The energy scale was corrected using the C1s peak at $285.0 \mathrm{eV}$ as a charge reference [23]. Peak fitting analysis was achieved using Voigt profiles (lower limit at $80 \%$ up to $100 \%$ Gauss). A Shirley background was subtracted from all spectra. For peak fitting in the C1s energy level the binding energy limits have been set according to Table 1 [23]. O1s energy level spectra were fitted with two peaks with a fixed separation of $2 \mathrm{eV}$. Two samples of each wood were measured and a mean with standard deviation were calculated.

An oxygenated to unoxygenated carbon ratio $\left(\mathrm{C}_{\text {ox }} / \mathrm{C}_{\text {unox }}\right)$ was calculated using the following equation [24]:

$$
\frac{\mathrm{C}_{\mathrm{ox}}}{\mathrm{C}_{\text {unox }}}=\frac{\mathrm{C}_{\text {oxygenated }}}{\mathrm{C}_{\text {unoxygenated }}}=\frac{\mathrm{C}_{2}+\mathrm{C}_{3}+\mathrm{C}_{4}}{\mathrm{C}_{1}} .
$$

\section{XRD analysis}

The mineralogical composition of the samples was analysed by powder X-ray diffraction using a Philips X'Pert MPD PW 3040 diffractometer (Netherlands), equipped with a PW 3050/10 goniometer, divergence slit $0.5^{\circ}$, anti-scatter slit $0.5^{\circ}$, receiving slit $0.6 \mathrm{~mm}$, secondary graphite monochromator, mask $15 \mathrm{~mm}$, operating at $40 \mathrm{kV}$ and $30 \mathrm{~mA}$ with $\mathrm{Cu} \mathrm{K} \alpha$ radiation. The range $5-50^{\circ} 2 \theta$ was scanned in continuous mode with a step width of $0.02^{\circ} 2 \theta$. The counting time was $4 \mathrm{~s}$ per step, sample spinning was at $1 \mathrm{rps}$. All samples were grinded in a planetary ball mill (P7 premium line, Fritsch) and prepared by back-loading in $16 \mathrm{~mm}$ sample holders. The assessment of the diffractograms was carried out with the X'Pert HighScorePlus 4.5 software (PANalytical). The crystallinity index (CrI) was calculated based on the following ratio [25]:

$$
\operatorname{Crl}[\%]=\frac{I_{200}-I_{\mathrm{am}}}{I_{200}} \times 100,
$$

where $I_{200}$ is the intensity of the crystalline peak at $2 \theta=22.5^{\circ}$, assigned to both crystalline and amorphous material, and $I_{\mathrm{am}}$ is the minimum intensity between the 200 and 101 peaks at $2 \theta=16.14^{\circ}$, assigned to the amorphous phase. Two measurements were performed for each sample group.

The apparent crystallite size was estimated using the Scherrer equation (3):

Table 1 Binding energy limits in the C1s energy level

\begin{tabular}{lll}
\hline C1s Peak & Lower Limit & Upper Limit \\
\hline C1 & 284.8 & 285.2 \\
C2 & 286.5 & 286.9 \\
C3 & 287.9 & 288.3 \\
C4 & 289.1 & 289.5 \\
\hline
\end{tabular}




$$
L=\frac{K \lambda}{\beta \cos \theta},
$$

where $K$ is a constant with the value of $0.94, \lambda$ is the $\mathrm{X}$-ray wavelength (1.54 nm for $\mathrm{Cu} \mathrm{K} \mathrm{K}_{\alpha}$ radiation), $\beta$ is the full width at half maximum of the diffraction band and $\theta$ is the Bragg angle corresponding to the (200) plane.

\section{Results and discussion}

\section{FTIR spectroscopy}

FTIR spectroscopy has been applied to identify changes in the chemical structure of cellulose, hemicelluloses, and lignin due to ageing of spruce and fir. The main bands of naturally aged and new wood samples in this study are listed in Table 2.

Figure 1 shows the ATR FTIR spectra of new and the two aged spruce wood samples. It is worth noting that the value of the standard deviation varies throughout the spectrum for the aged samples. Relatively high absorbance is found around bands that are prone to age-induced change. A small increase in the intensity around $3329 \mathrm{~cm}^{-1}$ assigned to $\mathrm{OH}$ groups is observed in aged wood. Changes in $\mathrm{OH}$ peaks can be caused by the absorption of moisture from the atmosphere by wood

Table 2 Main bands in FT-IR spectra of the studied wood samples

\begin{tabular}{|c|c|c|c|}
\hline Spruce & & Fir & \\
\hline $\begin{array}{l}\text { Wave number } \\
\left(\mathrm{cm}^{-1}\right)\end{array}$ & Assignments and remarks & Wave number $\left(\mathrm{cm}^{-1}\right)$ & Assignments and remarks \\
\hline 3329 & $\mathrm{OH}$ str & 3343 & $\mathrm{OH}$ str \\
\hline 2933 & $\mathrm{CH}$ str & 1733 & $\mathrm{C}=\mathrm{O}$ xylan, hemicellulose \\
\hline 2915 & $\mathrm{CH}$ str & 1603 & $\mathrm{C}=\mathrm{C}$ arom. lignin \\
\hline 1733 & $\mathrm{C}=\mathrm{O}$ xylan, hemicellulose & 1507 & $\mathrm{C}=\mathrm{C}$ arom. lignin \\
\hline 1604 & $\mathrm{C}=\mathrm{C}$ arom. lignin & 1420 & $\mathrm{CH} 2$ bend. cellulose (cryst 1, amorph) \\
\hline 1423 & $\mathrm{CH} 2$ bend. cellulose (cryst 1, amorph) & 1369 & $\mathrm{CH}$ bend. cellulose \\
\hline 1369 & $\mathrm{CH}$ bend. cellulose & 1335 & $\mathrm{OH}$ i.p.bend., $\mathrm{CH}$ cellulose, $\mathrm{CO}$ syringyl derivatives \\
\hline 1335 & $\mathrm{OH}$ i.p.bend., $\mathrm{CH}$ cellulose, $\mathrm{CO}$ syringyl derivatives & 1263,1398 & CO str., lignin, hemicellulose, guaiacyl ring \\
\hline 1265 & CO str., lignin, hemicellulose, guaiacyl ring & 1231 & syringyl ring vibr \\
\hline 1232 & syringyl ring vibr & 1157 & COC as. bridge, O str. cellulose, lignin, xylan \\
\hline 1156 & COC as. bridge, O str. cellulose, lignin, xylan & 1030 & CO cellulose, hemicellulose \\
\hline 1027 & CO cellulose, hemicellulose & 897 & as. o.o.ph. ring str. in cellulose \\
\hline 898 & as. o.o.ph. ring str. in cellulose & & \\
\hline
\end{tabular}

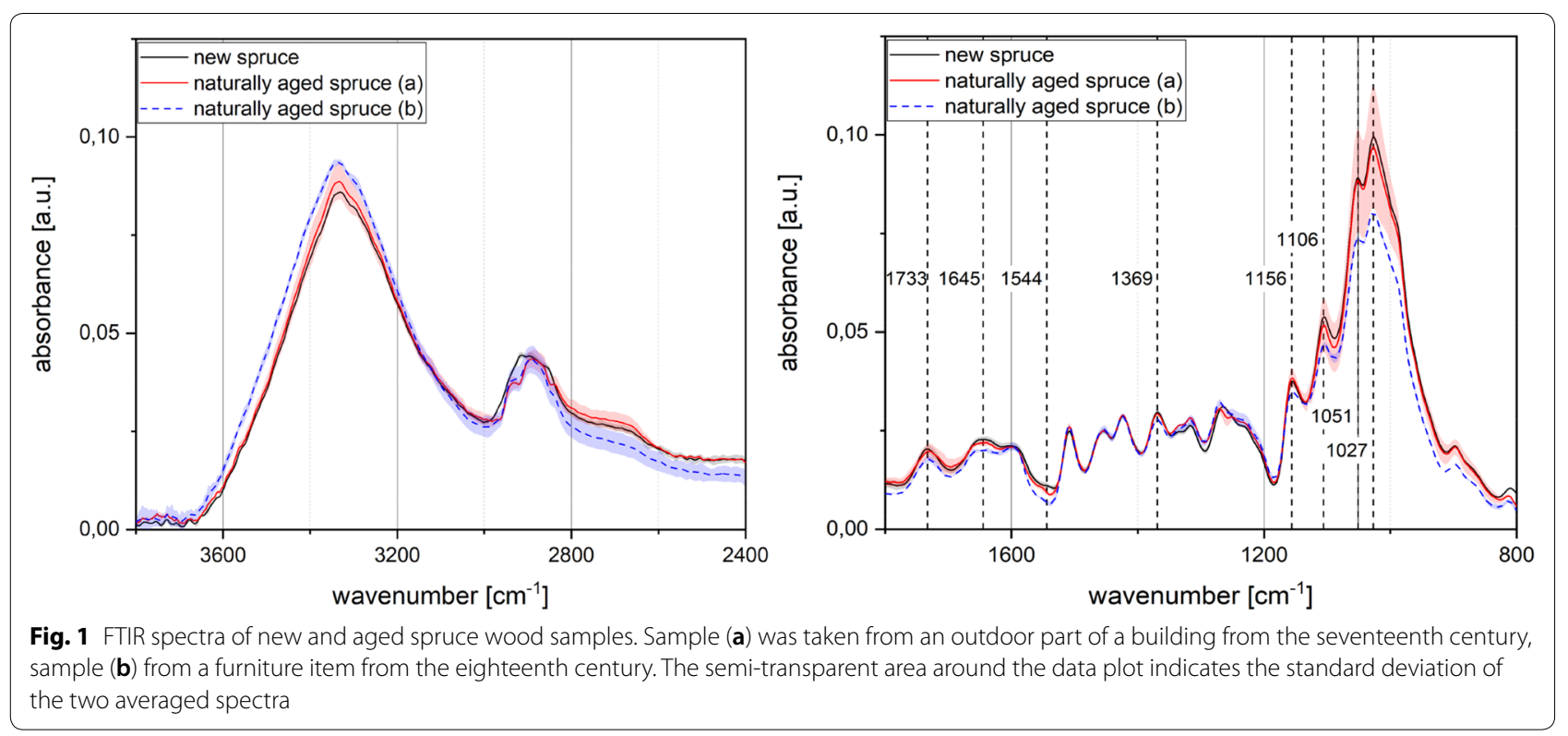


samples during measurement. In the area between 3000 and $2800 \mathrm{~cm}^{-1}$ the shape of the reference spectrum differs slightly from the aged samples spectra indicating changes in the aliphatic part of the molecules that cause band shifts. The peak at $1733 \mathrm{~cm}^{-1}$ belonging to the $\mathrm{C}=\mathrm{O}$ group in hemicelluloses does not exhibit significant differences to the reference spectrum. However, increased standard deviation values are found around this band, indicating that the age-induced intensity change of the carbonyl group is not uniform throughout the sample. At $1645 \mathrm{~cm}^{-1}$ the band of adsorbed $\mathrm{OH}$, $\beta$-glucosidic bonds or conjugated $\mathrm{C}=\mathrm{O}$ groups display lower intensity for aged spruce (b). A low intensity shoulder at $1544 \mathrm{~cm}^{-1}$ indicates $\mathrm{C}-\mathrm{O}$ in cellulose and hemicelluloses. This bond is subject to degradation as the intensity is somewhat lower for aged spruce (a) and significantly for aged spruce (b). A similar development can be observed in aged spruce (b) around $1369 \mathrm{~cm}^{-1}$, where the $\mathrm{CH}$ bending vibration of cellulose has an absorption maximum. At $1156 \mathrm{~cm}^{-1}$ the absorbance band assigned to $\mathrm{COC}$ bridge, $\mathrm{O}$ stretching vibration in cellulose, lignin and xylan is seen. Together with 1106, 1051, $1027 \mathrm{~cm}^{-1}$, mainly attributed to $\mathrm{CO}$ vibrations in hemicelluloses, these bands decrease significantly for aged spruce (b); for aged spruce (a) they exhibit a high standard deviation. These changes can be attributed to the degradation of cellulose and hemicellulose through ageing processes. Aged spruce (a) was sourced from an outdoor part of the building, which was subject to these environmental factors, unlike sample (b) that was taken from a furniture located indoors. Ganne-Che'deville et al. [26] studied naturally aged and artificially aged spruce wood samples. They found that natural ageing mostly affected the hemicelluloses and lignin, as observed from the FTIRATR spectra. Their results were contrary to our findings in this study. This difference can be due to environmental conditions and the impact of UV rays during the aging period. Also, the age of the samples can affect the amount of wood elements [1].

Figure 2 displays the ATR FTIR spectra of new and aged fir wood samples. While no significant changes can be observed for $\mathrm{OH}$ and $\mathrm{CH}$ above $2800 \mathrm{~cm}^{-1}$, some noticeable age-induced changes are visible in the fingerprint region between 1800 and $800 \mathrm{~cm}^{-1}$, where cellulose, hemicelluloses, and lignin have characteristic absorption peaks. The carbonyl group band in hemicelluloses near $1733 \mathrm{~cm}^{-1}$ decreased in intensity for aged fir. A shoulder at $1231 \mathrm{~cm}^{-1}$ attributed to the guaiacyl ring in lignin was lower in the aged sample. Apparently, this part of lignin is degrading over time. The $\mathrm{CH}$ bending vibrations at $1369 \mathrm{~cm}^{-1}$, the $\mathrm{OH}$ bending vibration of adsorbed water at $1335 \mathrm{~cm}^{-1}$ and the glucose ring stretching vibration at $1105 \mathrm{~cm}^{-1}$ are associated with cellulose. These bands do not show any significant changes in the aged sample indicating that there was no detectable degradation of cellulose. The band at $1030 \mathrm{~cm}^{-1}$ assigned to $\mathrm{CO}$ in cellulose or hemicelluloses showed lower intensity. The decline of this peak can be attributed to hemicelluloses alone, since the signals at 1369,1335 and $1105 \mathrm{~cm}^{-1}$, belonging to cellulose, do not show any age-induced change. The observations confirm the well-known fact that in case
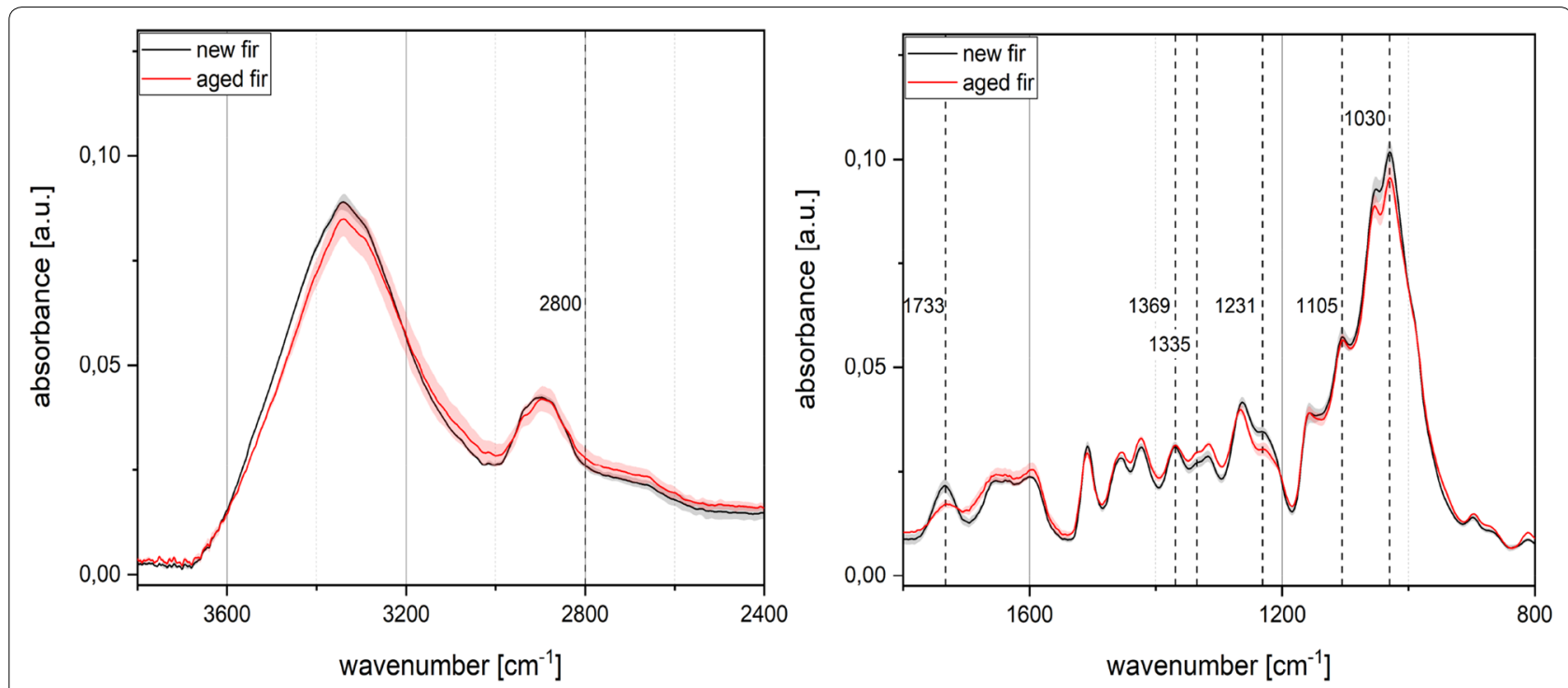

Fig. 2 FTIR spectra of new and aged fir wood samples. The semi-transparent area around the data plot indicates the standard deviation of the two averaged spectra 
of degradation of polysaccharides in wood, hemicelluloses are usually the first component to be degenerated [17]. Traoré et al. [27] have examined archaeological oak and pine wood from a ship. According to their results, the lignin content in the recent beam wood was significantly lower than in the old wood samples. Such variations can be due to differences in species between the two wood samples (oak and pine respectively). The researchers argue that the effect of environmental factors on the FTIR fingerprint has possibly been expressed in increased oxidation of lignin under aerated conditions (beam wood) and carbohydrate hydrolysis under submerged-anoxic conditions (shipwreck wood). The effect of environmental factors on the FTIR fingerprint has possibly been demonstrated by increased oxidation of lignin under aerated conditions (beam wood) and carbohydrate hydrolysis under submerged-anoxic conditions (shipwreck wood).

\section{XPS}

The C1s signal can be deconvoluted into four peaks labelled C1, C2, C3 and C4 [28]. The C1 sub-peak originates from carbon atoms bonded only to carbon or hydrogen in $\mathrm{C}-\mathrm{C}$ or $\mathrm{C}-\mathrm{H}$ bonds. The $\mathrm{C} 2$ signal represents carbon atoms with a single bond to oxygen, such as $\mathrm{C}-\mathrm{O}$ or $\mathrm{C}-\mathrm{O}-\mathrm{C}$. In wood, $\mathrm{C} 2$ mainly originates from carbohydrate and lignin constituents of wood and indicates the most abundant bond in cellulose [29]. The C3 peak is assigned to a carbonyl group or to a carbon atom bonded to two oxygen atoms such as $\mathrm{C}=\mathrm{O}$ or $\mathrm{O}-\mathrm{C}-\mathrm{O}$. The C4 peak is attributed to carboxyl groups.

Figure 3 presents $\mathrm{C} 1 \mathrm{~s}$ spectra for new spruce, aged spruce (a) and (b) as well as for new and aged fir. Table 3 indicates the corresponding surface composition within the $\mathrm{C} 1 \mathrm{~s}$ energy level.

The $\mathrm{C} 1$ sub-peak area shows a decrease after ageing, while the $\mathrm{C} 2$ and $\mathrm{C} 3$ area increased significantly. This
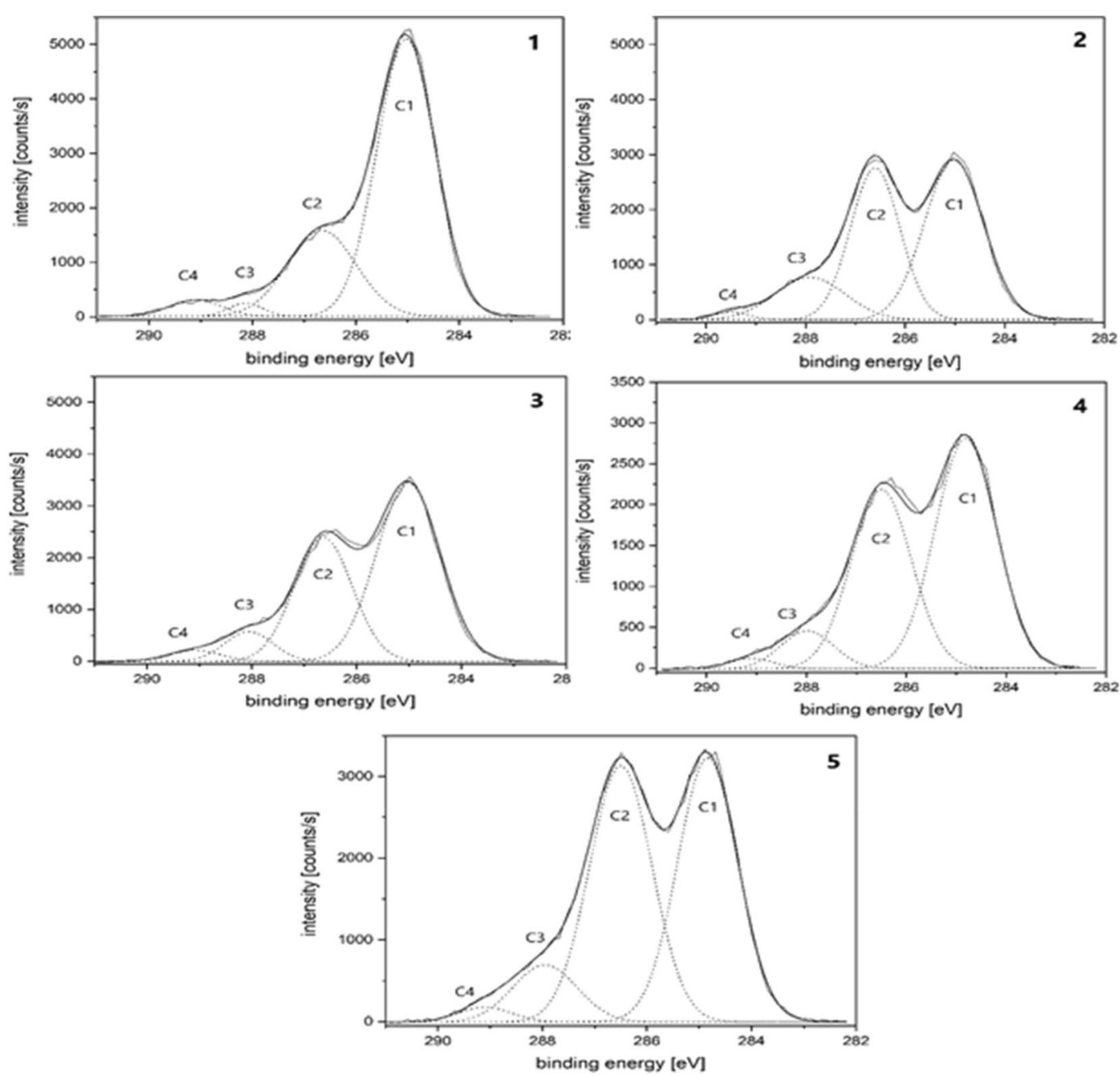

Fig. 3 High-resolution spectra of the C1s energy level of new spruce [1], aged spruce (a) [2], aged spruce (b) [3], new fir [4] and aged fir [5] samples 
Table 3 Relative surface composition for new and aged samples of spruce and fir

\begin{tabular}{|c|c|c|c|c|c|c|}
\hline Wood samples & C1 [atm.\%] & C2 [atm.\%] & C3 [atm.\%] & C4 [atm.\%] & $\begin{array}{l}\text { Atomic ratio } \\
\text { O/C }\end{array}$ & $C_{\text {ox }} / C_{\text {unox }}$ \\
\hline New spruce & $65.9( \pm 6.5)$ & $28.3( \pm 4.4)$ & $2.1( \pm 1.2)$ & $3.6( \pm 0.9)$ & 0.18 & 0.51 \\
\hline Aged spruce (a) & $43.2( \pm 4.7)$ & $45.0( \pm 2.3)$ & $9.8( \pm 2.8)$ & $2.1( \pm 0.4)$ & 0.42 & 1.31 \\
\hline Aged spruce (b) & $51.1( \pm 1.3)$ & $37.4( \pm 0.4)$ & $8.8( \pm 0.3)$ & $2.7( \pm 0.6)$ & 0.36 & 0.95 \\
\hline New fir & $48.5( \pm 2.9)$ & $39.5( \pm 2.3)$ & $9.5( \pm 1.0)$ & $2.5( \pm 0.4)$ & 0.36 & 1.06 \\
\hline Aged fir & $42.2( \pm 1.9)$ & $48.0( \pm 2.2)$ & $6.2( \pm 0.4)$ & $3.6( \pm 0.8)$ & 0.42 & 1.36 \\
\hline
\end{tabular}

indicates that the aged samples exhibit a higher concentration of oxygenated $\mathrm{C}$ atoms. In particular, the oxygenation of the surface occurs in the form of $\mathrm{C}-\mathrm{O}$ and $\mathrm{C}=\mathrm{O}$ bonds. The amount of carboxyl groups remains approximately the same during the ageing process. Similar ageing effects were observed in fir, even though they were not as pronounced as in spruce. In fir samples, the peak area of $\mathrm{C} 1$ decreased, while the area of $\mathrm{C} 2$ increased. Unlike in spruce, the $\mathrm{C} 3$ peak in aged fir exhibited a decrease indicating that the sample lost some of its $\mathrm{C}=\mathrm{O}$ or $\mathrm{O}-\mathrm{C}-\mathrm{O}$ bonds. The $\mathrm{O} / \mathrm{C}$ and $\mathrm{C}_{\text {ox }} / \mathrm{C}_{\text {unox }}$ ratios were both higher in all aged samples. The ratios for the spruce sample, which aged indoor, were higher than those for the one aged outdoor. These differences can be attributed to the influence of environmental factors like solar UV radiation, temperature fluctuations or biological decay causing surface degradation and oxidation of wood. For instance, under the influence of UV radiation lignin and cellulose are depolymerized [30]. In addition, hydrolysis surface reactions in the presence of moisture are taking place on wood components during ageing along with the removal of degraded carbon-containing compounds and extractives [30, 31].

Figure 3 presents the O1s energy level spectra for the analysed samples. The $\mathrm{O} 1$ sub-peak at $531 \mathrm{eV}$ originates from an oxygen atom linked to a carbon atom by a double bond, and the $\mathrm{O} 2$ peak at $533 \mathrm{eV}$ is attributed to an oxygen atom linked via a single bond to a carbon atom [30, 32]. As expected, the $\mathrm{O} 2$ component is more abundant, because it is the most frequently occurring carbon-oxygen type bond in lignin and cellulose. An ageing-related increase of the $\mathrm{O} 2$ peak area for both wood species was observed (Fig. 4).

These results indicate that depolymerization, oxidation and hydrolysis reactions occurred on the aged wood surface. It must be noted that the XPS results differ from the data collected by FTIR spectroscopy. In XPS, surface oxidation with an increased $\mathrm{O} / \mathrm{C}$ ratio was observed. In IR, the bands related to carbon-oxygen bonds decrease in intensity. Furthermore, with XPS a stronger surface degradation for the spruce sample aged outdoors was observed, while in IR, the indoor sample exhibited greater differences in relation to the reference [32, 33]. The results in this study are consistent with the findings of Popescu et al. [7]. The researchers observed significant changes in the first ageing period, the $\sim 150$-year lime wood sample having the highest percentage of carbon atoms and the lowest percentage of oxygen atoms, and the $\mathrm{O} / \mathrm{C}$ ratio, respectively. They clarified that these characteristics may be due to the fact that hemicelluloses and amorphous cellulose are degraded in time, while the crystalline cellulose fraction decreases more gradually than the amorphous fraction. Consequently, it may be found that under the environmental conditions, lignin is not so quickly degraded.

This illustrates the fact that the wood surface ages differently from the regions further away from the surface, exhibiting a distinct chemistry. Even though IR is considered a surface technique, it achieves an information depth that is orders of magnitude greater than XPS which analyses only the outermost layer.

\section{XRD}

The X-ray diffractograms of the studied new and aged wood samples are shown in Figs. 5 and 6. The diffractograms were deconvoluted using Gaussian profiles, to examine the intensities of the diffraction bands, to establish the crystalline and amorphous areas more exactly and to determine the crystallite size. The peak intensities and peak broadening differ from one species to another. The more pronounced difference occurs at the peak range between $20.50^{\circ}$ and $22.50^{\circ} 2 \theta$ reflection assigned with a crystallographic plane of cellulose. The $16.14^{\circ}-17.94^{\circ} 2 \theta$ reflection is assigned to the amorphous phase [34].

According to the results in Table 4, the crystallinity index (CrI) of the aged spruce (a) was higher than in new spruce, which is caused by the decomposition of amorphous regions in cellulose and hemicelluloses. The CrI of the aged spruce (b) and fir was lower than the respective references. This can be attributed to the removal of extractives and the effects of repeated moisture absorption and desorption cycles of ageing. Bryan et al. [25] have hypothesized that non-crystalline cellulose forms hydrogen bonds with cellulose at the surface of the 

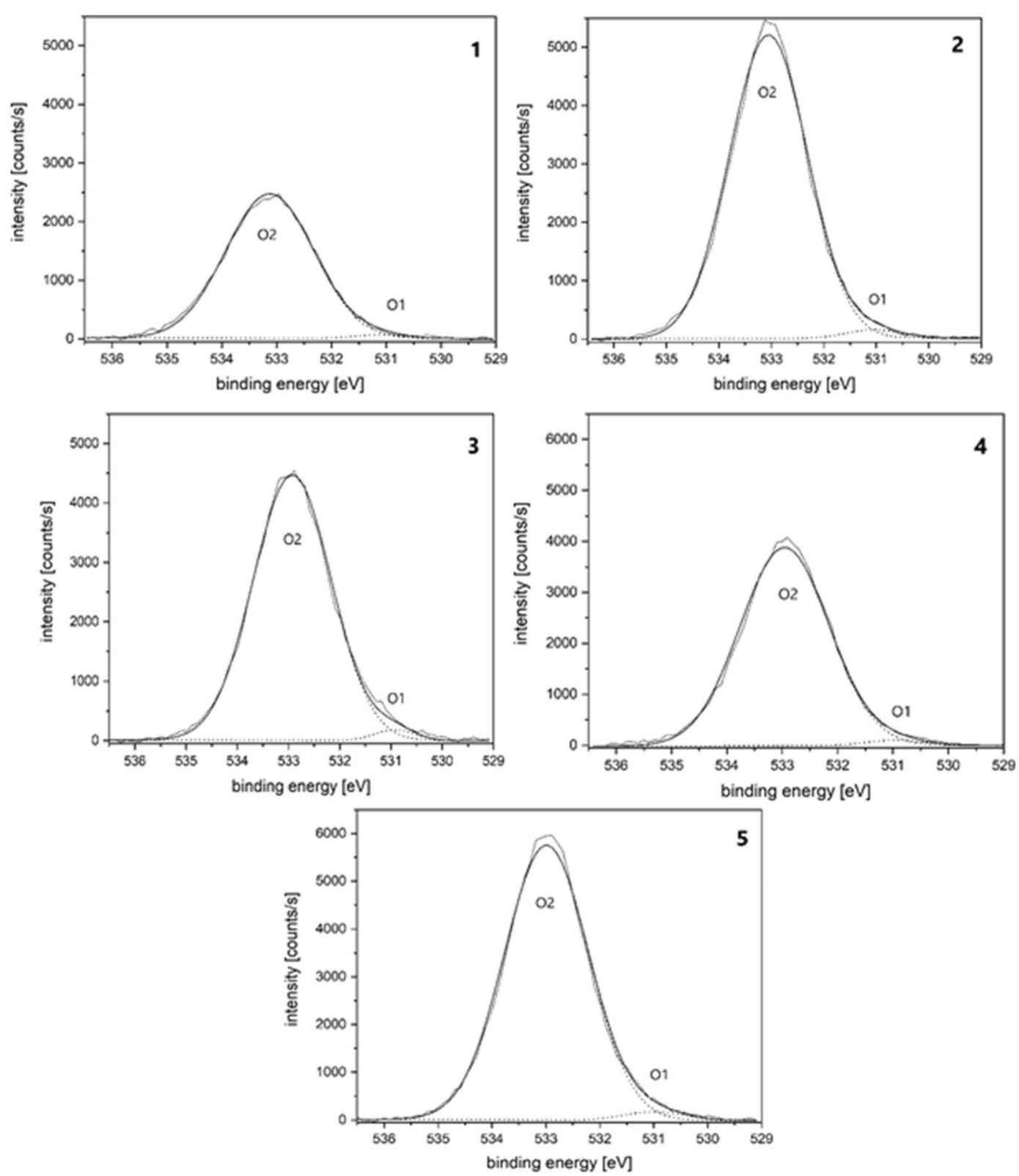

Fig. 4 High-resolution spectra of the O1s energy level of new spruce [1], aged spruce (a) [2], aged spruce (b) [3], new fir [4] and aged fir [5] samples

crystalline region due to the repeated moisture changes [34]. Contradictory results have been reported on the effects of natural ageing on the crystallinity of wood [4], which may be due to different wood species, ageing conditions and ageing time.

Since aged spruce (a) was sourced from an outdoor part of a building, this sample was more affected by environmental conditions such as high moisture, UV radiation, fungal decay and others. Thus, its crystallinity index was higher compared to other samples. The degree of cellulose crystallinity is one of the most important crystalline structure parameters. The rigidity of cellulose fibres increases and their flexibility decreases with increasing ratios of crystalline to amorphous regions According to Table 4, the CrI increased with increasing crystallite sizes, because the crystallites surface corresponding to amorphous cellulose regions diminished. This could be due to the chain conformation on the crystallite surface [34-38]. The crystallite sizes for aged spruce (a) and new fir are also higher, which confirms that CrI increased with increasing crystallite sizes, which is associated with a reduction of the amorphous domains. 


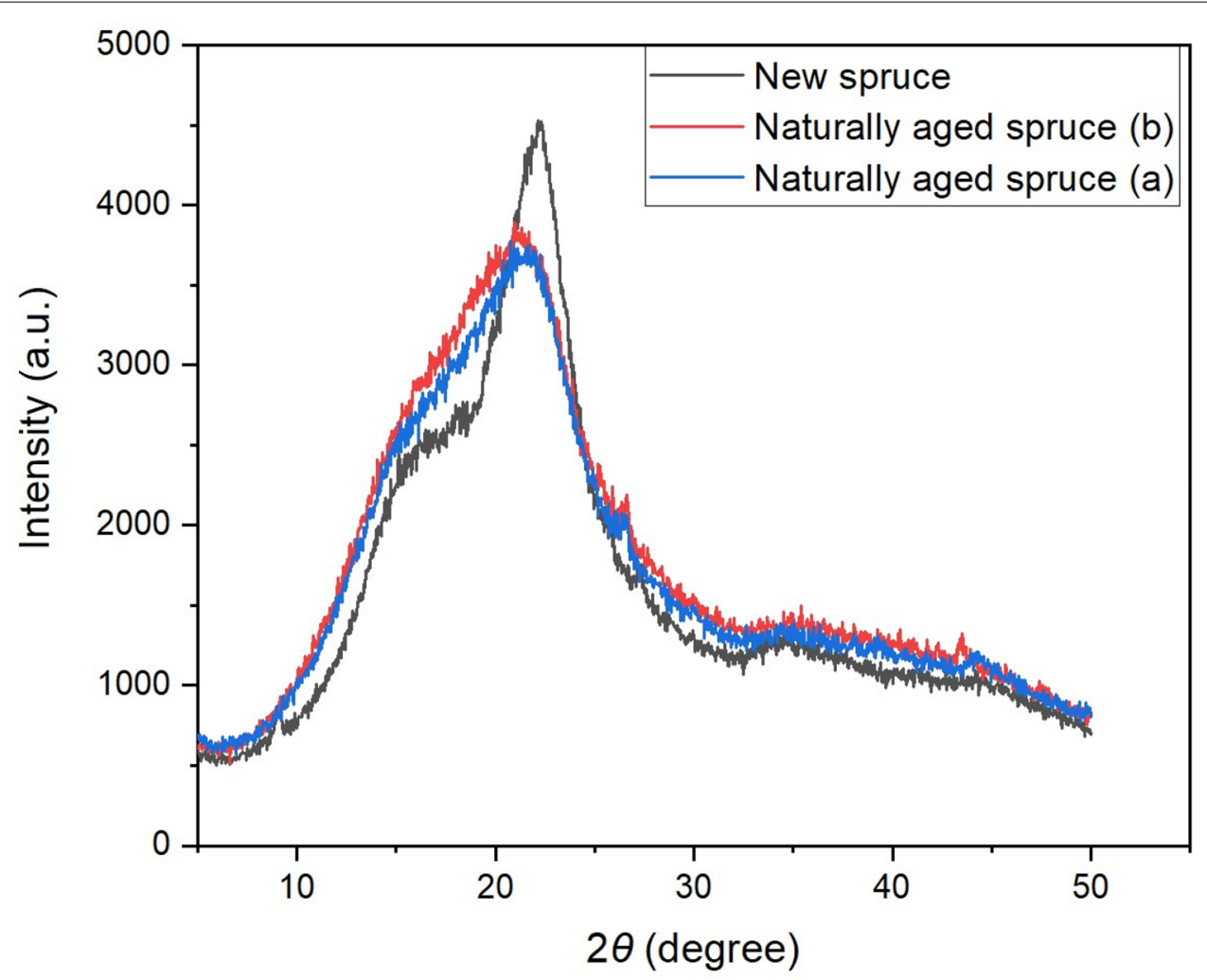

Fig. 5 X-ray diffractograms of new and the two aged spruce wood samples

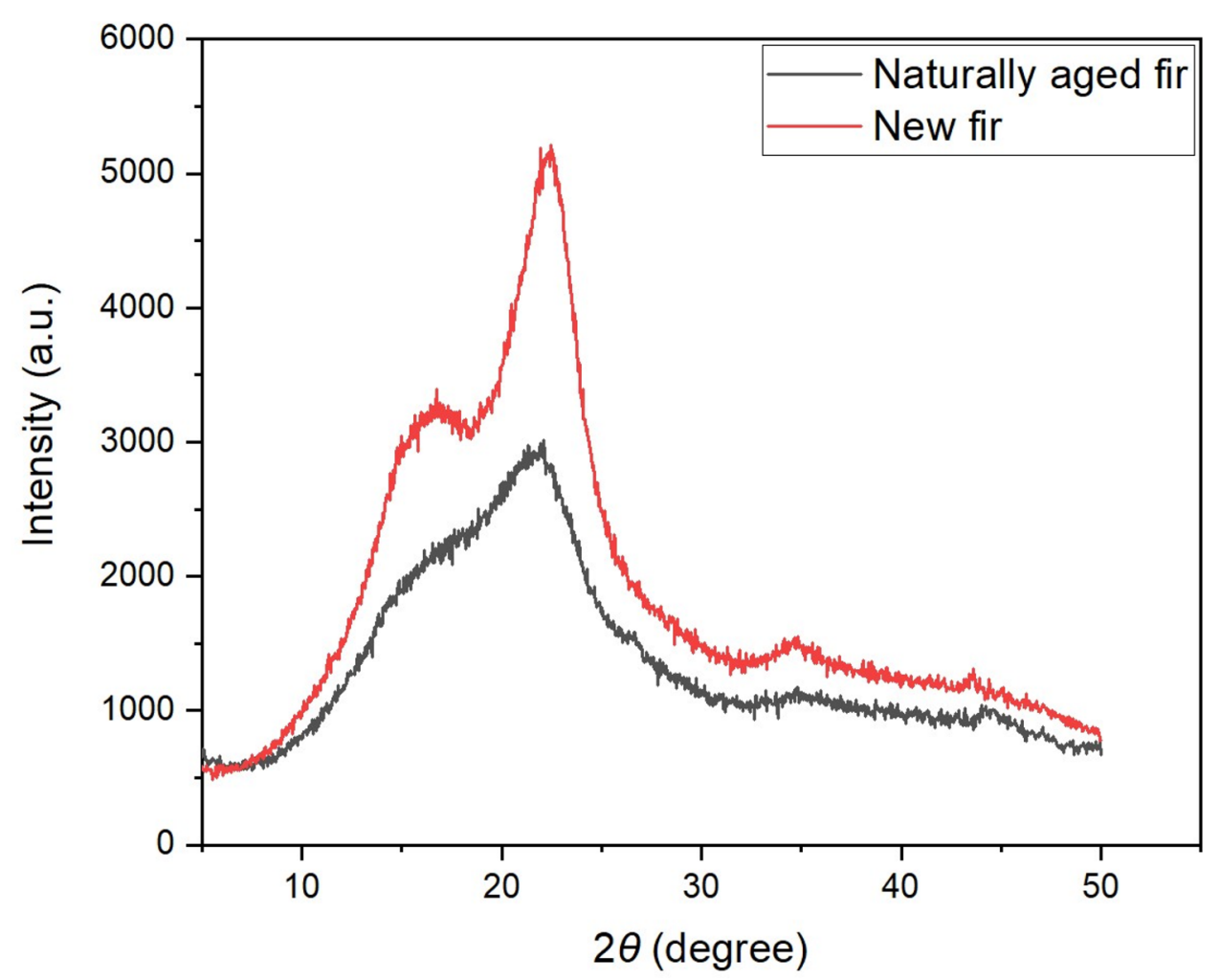

Fig. 6 X-ray diffractograms of new and aged fir wood 
Table 4 Band positions of crystalline and amorphous cellulose and the calculated parameters for the wood samples. $I_{200}$ is the maximum intensity of the crystalline cellulose, $l_{\mathrm{am}}$ is the minimum intensity of the crystalline cellulose, $\mathrm{Crl}$ is the crystalline index and $\mathrm{L}$ represents the crystallite size

\begin{tabular}{lllll}
\hline Wood samples & $\boldsymbol{I}_{\mathbf{2 0 0}}$ & $\boldsymbol{I}_{\mathbf{a m}}$ & $\mathbf{C r l} \mathbf{( \% )}$ & $\boldsymbol{L}(\mathbf{2 0 0})(\mathbf{n m})$ \\
\hline New spruce & 20.74 & 16.14 & 33.11 & 8.02 \\
Aged spruce (a) & 22.14 & 17.10 & 45.70 & 9.11 \\
Aged spruce (b) & 20.94 & 16.54 & 26.76 & 7.97 \\
New fir & 22.46 & 17.94 & 42.19 & 8.24 \\
Aged fir & 22.10 & 17.50 & 30.79 & 8.17 \\
\hline
\end{tabular}

\section{Conclusion}

This work established the main chemical differences between new and naturally aged European spruce (Picea abies) and silver fir (Abies alba) woods studied with ATRFTIR spectroscopy, X-ray photoelectron spectroscopy and XRD.

According to the FTIR analysis, the main age-induced changes in fir are the degradation of $\mathrm{C}-\mathrm{O}$ and $\mathrm{C}=\mathrm{O}$ groups in hemicellulose. For spruce, degradation of cellulose and hemicelluloses was observed with a greater effect seen in the sample aged indoor.

XPS analysis indicated that depolymerization, oxidation and hydrolysis reactions occurred on the aged wood surfaces, exhibiting higher $\mathrm{C}_{\mathrm{ox}} / \mathrm{C}_{\text {unox }}$ and $\mathrm{O} / \mathrm{C}$ ratios in aged wood. These ratios for the indoor-aged sample were higher than for the one aged outdoor showing the influence of weathering on the surface sample. The XPS results differed from the IR spectroscopy data due to different information depths of the two techniques. It was observed that the wood surface is oxidised, while no or little oxidation effects are seen deeper into the sample.

XRD measurements revealed that the aged fir and spruce (b) wood exhibited both lower crystallinity index and crystalline peak intensities. However, in aged spruce (a) the crystallinity index and crystalline peak intensity were higher due to the decomposition of the amorphous regions in cellulose and hemicelluloses and the crystallisation of amorphous cellulose caused by weathering.

\footnotetext{
Abbreviations

XPS: X-ray photoelectron spectroscopy; Crl: Crystallinity index; XRD: X-ray diffraction; UV: Ultraviolet radiation; ESCA: Electron spectroscopy for chemical analysis; ATR-FTIR: Attenuated total reflectance Fourier-transform infrared spectroscopy; FWHM: Full width at half maximum; eV: The electronvolt; W: Watt.
}

Acknowledgements

Not applicable.
Authors' contributions

Not applicable.

\section{Funding}

The German Federal Ministry of Education and Research (BMBF), Grant no. 13FH6I01IA, and the German Research Foundation (DFG), Grant no. INST 196/13-1.

\section{Availability of data and materials \\ The datasets used and/or analysed during the current study are available from the corresponding author on reasonable request. \\ Competing interests \\ The authors declare that they have no competing interests. \\ Author details \\ ${ }^{1}$ Doctoral School of Geosciences, Alexandru loan Cuza University of lasi, lasi, Romania. ${ }^{2}$ Faculty of Natural Sciences and Technology, University of Applied Sciences and Arts HAWK, Goettingen, Germany. ${ }^{3}$ Geoscience Centre, Georg- August-University Göttingen, Göttingen, Germany. ${ }^{4}$ Wood Biology and Wood Products Burckhardt Institute, Georg-August-University Göttingen, Göttingen, Germany. ${ }^{5}$ Faculty of Natural Resources, Department of Wood and Paper Science and Technology, University of Tehran, Tehran, Iran. ${ }^{6}$ Institute of Inter- disciplinary Research, Alexandru loan Cuza University of lasi, lasi, Romania. \\ ${ }^{7}$ Romanian Inventors Forum, lasi, Romania.}

Received: 8 July 2020 Accepted: 23 October 2020

Published online: 03 November 2020

\section{References}

1. Spiridon P, Sandu ICA, Nica L, lurcovschi CT, Colbu DE, Negru IC, Vasilache V, Cristache RA, Sandu I (2017) Archaeometric and chemometric studies involved in the authentication of old heritage artefacts II. Old linden and poplar wood put into work. Rev Chim 68(10):2422-2430

2. Sandu ICA, Luca C, Sandu I, Atym P (2001) Research regarding the soft wood supports degradation evaluation in old painting, using preparation layers. I. Chemical composition and technical analysis. Rev Chim 52(1-2):46-52

3. Hill CAS (2007) Wood modification: chemical, thermal and other processes. Wiley, Chichester

4. Kránitz K, Sonderegger W, Bues CT, Niemz P (2016) Effects of aging on wood: a literature review. Wood Sci Technol 50(1):7-22

5. Stamm AJ (1964) Wood and cellulose science. The Ronald Press Company, New York, p 1964

6. Rowell RM (1983) Chemical modification of wood. For Prod Abstracts 6(12):363-382

7. Popescu CM, Tibirna CM, Vasile C (2009) XPS characterization of naturally aged wood. Appl Surf Sci 256(5):1355-1360

8. Saini JK, Saini R, Tewari L (2015) Lignocellulosic agriculture wastes as biomass feedstocks for second-generation bioethanol production: Concepts and recent developments. 3 Biotech 5:337-353. https://doi.org/10.1007/ s13205-014-0246-5

9. Chundawat SP, Beckham GT, Himmel ME, Dale BE (2011) Deconstruction of lignocellulosic biomass to fuels and chemicals. Annu Rev Chem Biomol Eng 2:121-145. https://doi.org/10.1146/annurev-chembioeng-06101 0-114205

10. Tokareva EN, Faradim P, Pranovich AV, Fagerholm HP, Daniel G, Holmbom B (2007) Imaging of wood tissue by ToF-SIMS: Critical evaluation and development of sample preparation techniques. Appl Surf Sci 253:7569-7577

11. Zavarin E (1984) Activation of wood surface and nonconventional bonding. In: The Chemistry of Solid Wood, Chapter 10. American Chemical Society, Washington, D.C.

12. Nussbaum RM (1999) Natural surface inactivation of Scots pine and Norway spruce evaluated by contact angle measurements. Holz als Roh- und Werkstoff 57(6):419-424

13. Back EL (1991) Oxidative activation of wood surfaces for glue bonding. For Prod J 41(2):30-36 
14. Andrade JD, Gregonis DE, Smith LM (1985) Polymer surface dynamics. In: Surface and Interfacial Aspects of Biomedical Polymers. Vol. 1. Surface Chemistry and Physics. Plenum Press, New York.

15. Gardner DJ, Wolcott MP, Wilson L, Huang Y, Carpenter M (1995) Our understanding of wood surface chemistry in 1995. Proc. No. 7296. Wood Adhesives 1995. Forest Products Society: Madison, WI, USA.

16. Wålinder MEP, Ström G (2001) Measurement of wood wettability by the Wilhelmy method. Part 2. Determination of apparent contact angles. Holzforschung 55(1):33-31

17. Gelbrich J, Mai C, Militz H (2008) Chemical changes in wood degraded by bacteria. Int Biodet Biodeg 61:24-32

18. Beyer M, Kranitz K, Bremer M, Peters J, Fischer S, Bues CT, Niemz P (2018) Effect of natural aging on the chemical composition of Norway spruce, fir, and European oak wood. Pro Ligno 14:3-19

19. Huang C, Su Y, Shi J, Yuan C, Zhai S, Yong Q (2019) Revealing the effects of centuries of ageing on the chemical structural features of lignin in archaeological fir woods. New J Chem 43(8):3520-3528

20. Dorris GM, Gray DG (1978) The surface analysis of paper and wood fibres by ESCA. II. Surface composition of mechanical pulps. Cellulose Chem Technol 12:721-734

21. Strom G, Carlsson G (1992) Wettability of kraft pulps—effects of surface composition and oxygen plasma treatment. J Adhes Sci Technol 6:745-763

22. Wang X, Fei B, Ren H (2009) FTIR spectroscopic studies of the photodiscoloration of Chinese fir. Spectrosc Spectral Anal 29(5):1272-1275

23. Jusoh IB, Nzokou P, Kamdem P (2005) The effect of silicone on some properties of flakeboard. Holz Roh Werkst 63:266-271

24. Peng Y, Liu R, Cao J (2015) Characterization of surface chemistry and crystallization behavior of polypropylene composites reinforced with wood flour, cellulose, and lignin during accelerated weathering. Appl Surf Sci 332:253-259

25. Bryne LE, Lausmaa J, Ernstsson M, Englund F, Wålinder MEP (2010) Ageing of modified wood. Part 2: determination of surface composition of acetylated, furfurylated, and thermally modified wood by XPS and ToF-SIMS. Holzforschung 64(3):305-313. https://doi.org/10.1515/hf.2010.062

26. Ganne-Chédeville $C$, Jääskeläinen AS, Froidevaux J, Hughes M, Navi P (2012) Natural and artificial ageing of spruce wood as observed by FTIRATR and UVRR spectroscopy. Holzforschung 66(2):163-170

27. Traoré M, Kaal J, Cortizas AM (2016) Application of FTIR spectroscopy to the characterization of archeological wood. Spectrochim Acta Part A Mol Biomol Spectrosc 153:63-70
28. Bodîrlău R, Teacă CA (2009) Fourier transform infrared spectroscopy and thermal analysis of lignocellulose fillers treated with organic anhydrides. Rom J Phys 54(1):93-104

29. Barry AO, Zoran Z (1990) Surface analysis by ESCA of sulfite post-treated CTMP. J Appl Polym Sci 39:31-42

30. Cheng S, Huang A, Wang S, Zhang Q (2016) Effect of different heat treatment temperatures on the chemical composition and structure of Chinese Fir Wood. BioResources 11(2):4006-4016

31. Liu FPP, Rials TG, Simonsen J (1998) Relationship of wood surface energy to surface composition. Langmuir 14:536-541

32. Nzokou P, Kamdem DP (2005) X-ray photoelectron spectroscopy study of red oak-(Quercus rubra), black cherry-(Prunus serotina) and red pine(Pinus resinosa) extracted wood surfaces. Surf Interf Anal 37:689-694

33. Prégent J, Vandsburger $L$, Blanchard V, Blanchet P, Riedl B, Sarkissian A Stafford $L$ (2015) Determination of active species in the modification of hardwood samples in the flowing afterglow of N2 dielectric barrier discharges open to ambient air. Cellulose 22:811-827

34. Lionetto F, Sole RD, Cannoletta D, Vasapollo G, Maffezzoli A (2012) Monitoring wood degradation during weathering by cellulose crystallinity. Materials 5:1910-1922. https://doi.org/10.3390/ma5101910

35. Popescu CM, Dobele G, Rossinskaja G, Dizhbite T, Vasile C (2007) Degradation of lime wood painting supports. Evaluation of changes in the structure of aged lime wood by different physico-chemical methods. J Anal Appl Pyrol 79:71-77

36. Esteban LG, Fernandez FG, Garcia F, Casasus AG, Palacios PP, Gril J (2006) Comparison of the hygroscopic behavior of 205-year-old and recently cut juvenile wood from Pinus sylvestris L. Ann For Sci 63:309-317. https://doi. org/10.1051/forest:2006010

37. Park S, Baker JO, Himmel ME, Parilla PA, Johnson DK (2010) Cellulose crystallinity index: measurement techniques and their impact on interpreting cellulose performance. Biotechnol Biofuels 3:1-10. https://doi. org/10.1186/1754-6834-3-10

38. Zhao C, Zhang X, Liu L, Yu Y, Zheng W, Song P (2019) Probing chemical changes in holocellulose and lignin of timbers in ancient buildings. Polymers (Basel) 11(5):809

\section{Publisher's Note}

Springer Nature remains neutral with regard to jurisdictional claims in published maps and institutional affiliations.

\section{Submit your manuscript to a SpringerOpen ${ }^{\circ}$ journal and benefit from:}

- Convenient online submission

- Rigorous peer review

- Open access: articles freely available online

- High visibility within the field

Retaining the copyright to your article

Submit your next manuscript at springeropen.com 